\title{
Social support and diabetes self-management behavior among Caribbean, Caribbean American, and African American women: A descriptive correlation study
}

\author{
Idethia Shevon Harvey, Ledric Sherman, Erica Spears, Chanee Ford ${ }^{1}$, Helena Danielle Green ${ }^{2}$ \\ Department of Health and Kinesiology, Texas A and M University, College Station, TX, ${ }^{1}$ Department of Human Development and Family Studies, \\ University of Connecticut, Storrs, ${ }^{2}$ The Institute for Community Research, Hartford, CT, USA
}

\section{A B S T R A C T}

Background: Type-2 diabetes (T2D) is one of the most prevalent chronic and noncommunicable conditions both domestically and globally. The objective of this descriptive study was to examine how perceived social support impacted self-care management behavior among female African American and Caribbean populations. Materials and Methods: The cross-sectional study recruited 42 African American and Caribbean women diagnosed with T2D $(M=69.1, S D=12.0)$. Univariate and bivariate analyses were conducted to explore the relationship between (I) demographic characteristics, (2) desired and received social support variables, and (3) self-management behaviors. Results: Caribbean women residing in the United States were more likely to follow general diet $(M=5.38, S D=1.43)$ and to engage in physical activity $(M=4.3 \mathrm{I}, \mathrm{SD}=2.39)$, whereas African American women were more likely to follow a specific diabetes diet $(M=3.79$, $S D=1.60)$ and to monitor their glucose $(M=5.70, S D=1.75)$. Caribbean women living in the United States Virgin Islands were more likely to follow recommended foot care procedure $(M=4.65, S D=1.36)$. A negative correlation occurred between female participants exercising and the desired support in exercising. Women who reported that they desired more support with physical activity exercised less $\left(r_{s}=-0.34 ; P=0.04\right)$. No relationship was found between foot care procedure and demographic characteristics or social support variables (i.e. desired or received). Conclusion: This study suggests directions for future studies that would examine the dynamics of social support and T2D self-management behaviors, and this study might be relevant to other Caribbean and African American communities with T2D both in North America and the Caribbean.

Key words: Diabetes, minority women, self-management, social support

\section{INTRODUCTION}

Type-2 diabetes (T2D) is one of the most prevalent chronic and noncommunicable conditions globally and domestically. This lifelong chronic disease impacts nearly

\begin{tabular}{|l|l|}
\hline \multicolumn{2}{|c|}{ Access this article online } \\
\hline Quick Response Code: & Website: \\
\hline & www.josh.net \\
\hline
\end{tabular}

347 million individuals worldwide,,$^{[1]}$ and it continues to escalate in diagnosis and symptomatology. ${ }^{[2,3]}$ With the expected population growth, increased aging population,

\begin{abstract}
This is an open access article distributed under the terms of the Creative Commons Attribution-NonCommercial-ShareAlike 3.0 License, which allows others to remix, tweak, and build upon the work non-commercially, as long as the author is credited and the new creations are licensed under the identical terms.
\end{abstract}

For reprints contact: reprints@medknow.com

How to cite this article: Harvey IS, Sherman L, Spears E, Ford C, Green HD. Social support and diabetes self-management behavior among Caribbean, Caribbean American, and African American women: A descriptive correlation study. J Soc Health Diabetes 2017;5:16-24.

Corresponding Author: Dr. Idethia Shevon Harvey, Department of Health and Kinesiology, Texas A and M University, Blocker Building, 4243 TAMU, College Station, TX 77843-4243, USA. E-mail: idethia.harvey@hlkn.tamu.edu 
and urbanization with associated lifestyle change, researchers have predicted $54 \%$ global increase in the diagnosis of T2D by 2030. ${ }^{[3]}$ Of the four classifications for diabetes mellitus, T2D accounts for more than 90\% of individuals being diagnosed with diabetes ${ }^{[4.7]}$ Although T2D affects a larger part of the world population, some populations are disproportionately impacted by T2D. ${ }^{[3,8]}$

As a racial group, African Americans have the highest burden for T2D in the United States. It is estimated that $13.2 \%$ of African Americans are diagnosed with T2D as compared to $7.6 \%$ of non-Hispanics Whites. ${ }^{[9]}$ Foreign-born Blacks (i.e., Afro-Caribbeans) are often included in this statistic. ${ }^{[10]}$ The average prevalence of T2D is estimated to be approximately $9 \%$ in the Caribbean countries. ${ }^{[11,12]}$ Similar to the African American population in the United States, the Black Caribbeans in the United States Virgin Islands (USVI) are more likely to have diabetes than their counterparts in other Caribbean islands. ${ }^{[12-16]}$

Besides the high prevalence of T2D among African Americans and Black Caribbeans, this population also confronts similar complications, such as low health literacy, health beliefs, and accessibility of culturally sensitive information, all impediments which make it difficult to render proper care. ${ }^{[17]}$ Despite these barriers, social support has been shown to encourage and promote self-care management. ${ }^{[18]}$

\section{Theoretical background}

Seminal and current works have documented the protective effects of social support in the reduction of risk for mental and physical health. ${ }^{[19-21]}$ To understand how social relationships influence an individual's health and well-being, Kahn and Antonucci ${ }^{[22]}$ proposed the convoy model of social relationships. According to this model, individuals are surrounded by their social system. ${ }^{[22]}$ For this study, the convoy model suggests that as women move through life, they derive support, identification, and a sense of contentment and continuity from their social relationships. ${ }^{[22,23]}$ An individual convoy of relationships is predicated on the reactions to and expectations of support. ${ }^{[24]}$ In terms of gender, women reported (1) having more frequent contact within their social system, (2) having larger and more multifaceted social networks, (3) having more satisfying relationships with their friends, and (4) providing more support than men offer. ${ }^{[25]}$ As women age and confront a myriad of chronic conditions, their close relationships (i.e. family and/or friends) are likely to affect their ability to adapt to the challenges they encounter along the health continuum. ${ }^{[26,27]}$
Social support and type-2 diabetes management

Social support is an intricate concept, which coincides with multiple social networks (i.e., family, occupation, community, and institution) surrounding an African American woman. Social support has the potential to exert more positive than negative influences on the woman's ability to self-manage her condition. ${ }^{[28-33]}$ Researchers have found that families often play a key role in the everyday instrumental tasks of diabetes care, especially within minority families. ${ }^{[31,34]}$ Social support has been examined in diverse forms as it relates to the facilitation and hindrance of female patients' self-management of chronic diseases. ${ }^{[31,33,35-37]}$ In a qualitative study, Madden et al. ${ }^{[37]}$ found that women diagnosed with T2D were more likely to successfully manage their conditions - if a family member had been previously diagnosed with T2D - than those women without a family member previously diagnosed with T2D. Likewise, in a sample of 46 women, DePalma et al. ${ }^{[36]}$ found that negative family interaction predicted ineffective diabetes management, such as diet and glucose monitoring.

Although studies have focused on social support within the female African American or Black female Caribbean populations, ${ }^{[13,17,32,34]}$ research has been sparse in investigating diabetes-specific social support of both Black female Caribbean and African American female populations residing in the United States or part of the US territories (i.e. USVI). To fill the gap in the literature, the purpose of this study is to examine the perceived social support and its effects on self-care management practices among female African American and Black female Caribbean populations.

\section{Materials And Methods}

\section{Design}

This study employed a descriptive, cross-sectional design to explore the relationship between the respondents' self-management behavior and their perceived social support. Participants were recruited from health and humans services facilities (i.e., senior centers and senior apartment buildings) in the USVI and Connecticut. To participate in the study, women (1) had to self-identify as being either Black female Caribbean or female African American, (2) had to be diagnosed with T2D for more than 6 months, and (3) had to be 45 years of age or older. Data collection consisted of participant demographics, social networks and social support, general health status, comorbidities and index disease, and self-management patterns. We expected a small sample size in our recruitment efforts. Many factors influenced 
the sample size of the study. For example, the authors had to consider the recruitment logistics among Caribbean women internationally and domestically as well as the cost of implementing the study. Although the sample size is small, it is deemed acceptable because the study focused on assessing clarity of survey and ease of administration. ${ }^{[38]}$

\section{Ethics approval}

All procedures for this research project were approved by the Protection of Human Subjects Division of the Institutional Review Board at the University of Connecticut and the University of the Virgin Islands (e.g., IRB \#H13-154, IRB \#H13-316, and IRB \# H11-215 PITT, respectively). All participants reviewed and signed informed consent forms before participating in the study.

\section{Measures}

Measures for social support were based on a reliable and valid instrument, the Diabetes Care Profile (DCP), ${ }^{[39,40]}$ to assess the social and psychological factors related to T2D. Scale reliabilities (i.e., Cronbach's $\alpha$ ) ranged from 0.75 to $0.90 .{ }^{[39,40]}$ The DCP assessed the reliability among female African Americans with T2D (Cronbach's $\alpha=0.93$ ). ${ }^{[40]}$ The diabetes-specific support-received (DSSR) scale, ${ }^{[41,42]}$ a subscale of the DCP, assessed the extent to which these African American females received specific support from their social network in the following ways: (1) Following a meal plan, (2) taking medicine, (3) following a foot care procedure, (4) getting enough physical activity, (5) testing sugar levels, and (6) handling feelings about diabetes. A 5-point ordinal response format was used, with higher scores indicating greater amounts of support received (range 6-30). ${ }^{[41,42]}$ The study scale's internal consistency was adequate for an exploratory study - Cronbach's $\alpha=0.81 .{ }^{[43,44]}$

The diabetes-specific support-desired (DSSD) scale, ${ }^{[41,42]}$ a subscale of the DCP, assessed the extent to which these African American females desired assistance from their social networks in the form of tangible and emotional support. ${ }^{[42]}$ The items in this scale directly paralleled the DSSR scale. High scorers desired more support than low scorers (range $=6-30) \cdot{ }^{[41,42]}$ Cronbach's alpha for this scale was $0.79 .^{[43,44]}$

The summary of diabetes self-care activities (SDSCA) originally assessed five areas of T2D management behavior during the past 7 days: (1) General diet, (2) specific diet, (3) exercise, (4) blood glucose monitoring, and (5) foot care procedure. ${ }^{[45]}$ The Cronbach's $\alpha$ for the summary score was $0.71,0.42,0.71,0.87$, and 0.46 for each of the subscales, respectively. ${ }^{[45]}$ Modifications within the survey included adding items, such as medication compliance and smoking. ${ }^{[45]}$ The SDSCA has been used in several research studies. ${ }^{[46,47]}$

Data analysis

Before analysis, variables were tested for normality. Descriptive statistics were gathered on demographic characteristics, self-care activities, and diabetes-specific support variables. To simplify analysis, marital status, education, and employment status were recorded as follows: Marital status: 1= "Married," 2= "not married," and $3=$ "cohabiting;" education: $1=$ "High school graduate/general educational development or less" and 2 = "some college or more;" employment status: $1=$ "Working" and 2= "retired." A Chi-square analysis was performed to compare demographic characteristics and independent variables between the two groups. Bivariate analysis was conducted to explore the relationship between (1) demographic characteristics, (2) social support desired and received variables, and (3) self-management behaviors. If the parametric assumptions were met, the Pearson correlation coefficient was utilized to determine the relationship between variables measured on ratio or interval scales. To address the nonnormality of variable distributions, Spearman's rho correlational was used for bivariate analysis.

\section{RESULTS}

The participants' characteristics are compared by location as shown in Table 1. The mean age of the total sample was 69.1 years, with Black Caribbean women residing in the United States representing the oldest cohort $(P=0.39)$. Significant differences occurred in years of diagnosis and educational levels. African American women were more likely to have the longest length of T2D diagnosis $(P=0.050)$ and have an education beyond high school $(P=0.008)$. No significant differences were found in the body mass index (BMI), average and percentage of comorbidities, marital status, employment status, smoking behavior, and health status. Although the total sample was obese $\left(B M I=31.2 \mathrm{~kg} / \mathrm{m}^{2}\right)$, the BMI for Black Caribbean American women $\left(B M I=28.5 \mathrm{~kg} / \mathrm{m}^{2} ; P=0.27\right)$ was less compared to Black Caribbean women residing in the USVI and African American women (BMI $=31.8 \mathrm{~kg} / \mathrm{m}^{2}$, $32.0 \mathrm{~kg} / \mathrm{m}^{2}$, respectively). Furthermore, Black Caribbean American women were more likely to be married (25\%), and they were more likely not to smoke than their counterparts. Black Caribbean women living in the USVI were more likely to report the most comorbidities $(\mathrm{M}=3.8)$. African American women were more likely to be retired (90\%).

Although no significant differences between the independent variables existed [Table 2], Black female 


\begin{tabular}{|c|c|c|c|c|c|}
\hline Characteristics & Total sample $(n=42)$ & Caribbean US residents $(n=8)$ & African Americans $(n=10)$ & USVI (n=24) & $\boldsymbol{P}$ \\
\hline Age (years), mean (SD) & $69.1(12.0)$ & $74.0(8.4)$ & $66.3(13.3)$ & $68.6(12.4)$ & 0.39 \\
\hline $\mathrm{BMI}\left(\mathrm{kg} / \mathrm{m}^{2}\right)$, mean (SD) & $31.2(5.2)$ & $28.5(4.8)$ & $32.0(6.21)$ & $31.8(4.8)$ & 0.27 \\
\hline Years of diagnosis, mean (SD) & $13.3(6.7)$ & $12.2(4.6)$ & $17.9(8.7)$ & $11.6(6.1)$ & 0.05 \\
\hline Comorbidities, mean (SD) & $3.6(1.5)$ & $3.2(1.7)$ & $3.5(1.3)$ & $3.8(1.5)$ & 0.56 \\
\hline \multicolumn{6}{|l|}{ Marital status } \\
\hline Married & 16.7 & 25 & 20 & 12.5 & 0.65 \\
\hline Not married & 78.6 & 62.5 & 80 & 83.3 & \\
\hline Cohabitation & 4.8 & 12.5 & 0.0 & 4.2 & \\
\hline \multicolumn{6}{|l|}{ Education } \\
\hline$<$ High school & 69.0 & 62.5 & 30.0 & 87.5 & 0.008 \\
\hline$>$ High school & 31.0 & 37.5 & 70.0 & 12.5 & \\
\hline \multicolumn{6}{|l|}{ Employment status } \\
\hline Working & 19.0 & 37.5 & 10.0 & 16.7 & 0.30 \\
\hline Retired & 81.0 & 62.5 & 90.0 & 83.3 & \\
\hline \multicolumn{6}{|l|}{ Comorbidities* } \\
\hline Hypertension & 90.5 & 100.0 & 100.0 & 83.3 & 0.64 \\
\hline Arthritis & 59.5 & 62.5 & 70.0 & 56.5 & 0.76 \\
\hline Depression & 28.6 & 14.3 & 30.0 & 38.1 & 0.50 \\
\hline Serious fall & 21.4 & 25.0 & 10.0 & 26.1 & 0.56 \\
\hline $\begin{array}{l}\text { Asthma/emphysema/ } \\
\text { COPD }\end{array}$ & 16.7 & 0.0 & 30.0 & 17.4 & 0.28 \\
\hline Stomach ulcers & 19.0 & 25.0 & 20.0 & 17.4 & 0.90 \\
\hline Other comorbidities & 30.9 & 12.5 & 30.0 & 26.0 & 0.66 \\
\hline \multicolumn{6}{|l|}{ Smoking } \\
\hline Yes & 5.0 & 0.0 & 10.0 & 4.5 & 0.62 \\
\hline No & 95.0 & 100.0 & 90.0 & 95.5 & \\
\hline \multicolumn{6}{|l|}{ Health status } \\
\hline Excellent/good & 55.0 & 62.5 & 59.1 & 40.0 & 0.29 \\
\hline Fair & 37.5 & 37.5 & 27.3 & 60.0 & \\
\hline Poor/very poor & 7.5 & 0.0 & 13.6 & 0.0 & \\
\hline
\end{tabular}

*Column total exceeds $100 \%$ because many subjects had more than one chronic condition. USVI: United States Virgin Islands, BMI: Body mass index, SD: Standard deviation, COPD: Chronic obstructive pulmonary disease

\begin{tabular}{|c|c|c|c|c|c|}
\hline Characteristics & Total sample $(n=42)$ & Caribbean US residents $(n=8)$ & African Americans $(n=10)$ & USVI ( $n=24)$ & $P$ \\
\hline General diet, mean (SD) & $4.68(1.72)$ & $5.38(1.43)$ & $5.28(1.28)$ & $4.17(1.45)$ & 0.12 \\
\hline Specific diet, mean (SD) & $3.22(1.64)$ & $3.09(1.66)$ & $3.79(1.60)$ & $3.00(1.67)$ & 0.45 \\
\hline Exercise, mean (SD) & $3.46(2.66)$ & $4.31(2.39)$ & $1.90(2.46)$ & $3.88(2.66)$ & 0.09 \\
\hline Glucose test, mean (SD) & $4.21(2.83)$ & $4.63(3.10)$ & $5.70(1.75)$ & $3.39(2.92)$ & 0.09 \\
\hline Medication, mean (SD) & $6.61(1.33)$ & $7.00(0.00)$ & $7.00(0.00)$ & $6.25(1.77)$ & 0.22 \\
\hline Foot care, mean (SD) & $4.41(1.44)$ & $3.69(1.39)$ & $4.45(1.59)$ & $4.65(1.36)$ & 0.27 \\
\hline DSSD total, mean (SD) & $13.67(6.69)$ & $11.13(7.70)$ & $12.70(5.66)$ & $15.10(6.69)$ & 0.32 \\
\hline DSSR total, mean (SD) & $15.23(6.72)$ & $12.63(5.97)$ & $12.70(5.92)$ & $17.43(6.82)$ & 0.08 \\
\hline
\end{tabular}

DSSD: Diabetes-specific support-desired; DSSR: Diabetes-specific support-received; USVI: United States Virgin Islands; SD: Standard deviation

Caribbeans residing in the United States were more likely to follow a general diet $(\mathrm{M}=5.38, \mathrm{SD}=1.43)$ and exercise $(\mathrm{M}=4.31, \mathrm{SD}=2.39)$, compared to African American and Black USVI women. African American female T2D patients were more likely to follow a specific diabetes diet $(\mathrm{M}=3.79, \mathrm{SD}=1.60)$ and glucose monitoring $(\mathrm{M}=5.70$, $\mathrm{SD}=1.75)$, compared to both Black Caribbean women living in the United States and the USVI. Both women residing in the United States (African American and Caribbean) self-reported $100 \%$ compliance in taking the medication as prescribed by their physicians. Black Caribbean women living in the USVI were more likely to follow a foot care procedure $(M=4.65, S D=1.36)$. It is important to note that DSSD $(\mathrm{M}=13.67, \mathrm{SD}=6.69)$ and DSSR $(M=15.23, S D=6.72)$ were low for the total sample.

Demographics and diabetes-specific support are correlated with diabetes self-care activities as shown in Table 3. The longer a woman was diagnosed with $\mathrm{T} 2 \mathrm{D}\left(r_{\mathrm{s}}=0.36 ; \mathrm{P}=0.03\right)$, the more likely she followed a general diet. A negative correlation occurred between the number of comorbidities and general diet. Participants who reported less than three comorbidities had healthier eating habits $\left(r_{\mathrm{s}}=-0.38\right.$; $P=0.03)$. Participants who reported a positive health status ate healthier foods $\left(r_{\mathrm{s}}=0.35 ; P=0.03\right)$. In addition, 


\begin{tabular}{|c|c|c|c|c|c|c|c|c|c|c|c|c|}
\hline \multirow[t]{3}{*}{ Variables } & \multicolumn{12}{|c|}{ Summary of diabetes self-care activities } \\
\hline & \multicolumn{2}{|c|}{ General diet } & \multicolumn{2}{|c|}{ Specific diet } & \multicolumn{2}{|c|}{ Exercise } & \multicolumn{2}{|c|}{ Glucose testing } & \multicolumn{2}{|c|}{ Medication } & \multicolumn{2}{|c|}{ Foot care } \\
\hline & $r$ & $\boldsymbol{P}$ & $r$ & $P$ & $r$ & $P$ & $r$ & $P$ & $r$ & $P$ & $r$ & $\boldsymbol{P}$ \\
\hline Age & 0.03 & 0.86 & -0.22 & 0.18 & 0.14 & 0.40 & 0.07 & 0.69 & 0.19 & 0.27 & 0.05 & 0.78 \\
\hline $\mathrm{BMI}$ & -0.29 & 0.09 & -0.22 & 0.19 & 0.03 & 0.85 & -0.09 & 0.57 & -0.01 & 0.10 & 0.24 & 0.14 \\
\hline Years of diagnosis & 0.36 & 0.03 & 0.07 & 0.70 & -0.18 & 0.29 & 0.38 & 0.02 & 0.00 & 0.99 & 0.19 & 0.25 \\
\hline Comorbidities & -0.38 & 0.02 & -0.16 & 0.37 & 0.04 & 0.84 & 0.15 & 0.38 & -0.17 & 0.34 & 0.15 & 0.39 \\
\hline Marital status & -0.02 & 0.93 & 0.11 & 0.49 & -0.04 & 0.82 & -0.25 & 0.12 & 0.16 & 0.35 & -0.27 & 0.09 \\
\hline Education & 0.22 & 0.20 & 0.38 & 0.02 & -0.25 & 0.13 & 0.07 & 0.67 & -0.01 & 0.97 & 0.13 & 0.44 \\
\hline Health status & 0.35 & 0.03 & 0.12 & 0.47 & 0.08 & 0.63 & 0.16 & 0.34 & 0.35 & 0.03 & -0.21 & 0.20 \\
\hline Help desired in meal plan & -0.02 & 0.93 & 0.04 & 0.04 & -0.01 & 0.96 & -0.06 & 0.71 & -0.27 & 0.11 & -0.19 & 0.24 \\
\hline Help desired in taking medications & -0.04 & 0.82 & 0.30 & 0.07 & 0.08 & 0.63 & -0.03 & 0.88 & -0.18 & 0.30 & 0.05 & 0.75 \\
\hline Help desired in taking care of feet & 0.12 & 0.46 & 0.36 & 0.02 & 0.15 & 0.36 & 0.01 & 0.97 & -0.03 & 0.13 & 0.06 & 0.73 \\
\hline Help desired in getting physical activity & -0.01 & 0.97 & 0.27 & 0.09 & -0.34 & 0.04 & -0.18 & 0.27 & -0.19 & 0.26 & -0.16 & 0.32 \\
\hline Help desired in testing glucose & -0.07 & 0.66 & 0.25 & 0.12 & -0.04 & 0.83 & -0.08 & 0.63 & -0.02 & 0.93 & -0.27 & 0.10 \\
\hline Help desired with feeling for T2D & 0.08 & 0.063 & 0.20 & 0.23 & 0.17 & 0.31 & 0.12 & 0.48 & -0.27 & 0.10 & 0.16 & 0.34 \\
\hline Help received in meal plan & 0.25 & 0.14 & 0.18 & 0.27 & 0.06 & 0.74 & 0.08 & 0.63 & -0.33 & 0.05 & -0.09 & 0.58 \\
\hline Help received in taking medications & -0.00 & 0.98 & 0.24 & 0.15 & -0.60 & 0.72 & -0.05 & 0.78 & -0.03 & 0.87 & -0.03 & 0.86 \\
\hline Help received in taking care of feet & -0.08 & 0.65 & 0.26 & 0.12 & 0.07 & 0.66 & -0.17 & 0.30 & -0.23 & 0.17 & 0.03 & 0.85 \\
\hline Help received in getting physical activity & 0.08 & 0.65 & 0.06 & 0.70 & 0.06 & 0.72 & 0.29 & 0.08 & -0.21 & 0.21 & 0.08 & 0.65 \\
\hline Help received in testing glucose & -0.11 & 0.52 & -0.05 & 0.78 & 0.19 & 0.26 & -0.14 & 0.40 & 0.02 & 0.89 & -0.07 & 0.69 \\
\hline Help received with feeling for $\mathrm{T} 2 \mathrm{D}$ & 0.06 & 0.72 & 0.12 & 0.46 & 0.13 & 0.43 & 0.06 & 0.72 & -0.27 & 0.10 & -0.21 & 0.21 \\
\hline
\end{tabular}

participants who had an education beyond high school $\left(r_{\mathrm{s}}=0.38 ; P=0.02\right)$ felt supported in meal planning $\left(r_{\mathrm{s}}=0.04\right.$; $P=0.04)$ and followed a foot care procedure $\left(r_{\mathrm{s}}=0.36\right.$; $P=0.02$ ). Participants were more likely to report that they followed dietary guidelines specific to managing T2D.

A negative correlation occurred between participants exercising and the desired support in exercising. Participants who reported that they desired more support with physical activity exercised less $\left(r_{s}=-0.34 ; P=0.04\right)$. Participants were more consistent in self-reported glucose monitoring, the longer they were diagnosed with T2D $\left(r_{\mathrm{s}}=0.38 ; P=0.02\right)$. Participants who reported positive health status were more likely to self-report adherence to a T2D medication regimen $\left(r_{\mathrm{s}}=0.35 ; P=0.03\right)$, but they were less likely to receive support in meal planning from friends and family members $\left(r_{s}=-0.33 ; P=0.05\right)$. No relationship was found between foot care procedure and demographic characteristics or between social support variables (i.e. desired or received).

\section{DISCUSSION}

The purpose of this study was to explore the relationship between diabetes-specific support and self-care management practices among female African American and Black female Caribbean populations. Because social support is a multidimensional concept, this study investigated T2D specific to desired and received social support variables. Research indicates that social interactions with family and friends play a significant role in diabetes management. These findings contrast to those reported in previous research, in which satisfied support was reported to be associated with better self-management behavior. Low social support or assistance among family members has a prominent impact on diabetes self-management. ${ }^{[36]}$ Vest et al. ${ }^{[48]}$ found that family members assisted in the day-to-day activities of T2D self-management behaviors. However, similar to prior studies, this study showed that women diagnosed with T2D often experienced conflicting demands in their day-to-day diabetes management. ${ }^{[34,49]}$ Social support therefore may not be uniformly and automatically beneficial among female caregivers. ${ }^{[17,47,50]}$ Special importance should be considered among women's social networks as they pertain to providing diabetes-specific social support to improve self-management behaviors. ${ }^{[51]}$

Unlike previously published findings, ${ }^{[26,27]}$ this study suggests that T2D-specific social support plays a minor role to specific T2D self-management behavior among those Black female Caribbean and female African American participants, except following a foot care procedure. However, certain findings in this study were consistent with other studies. Similar to Whittemore et al., ${ }^{[52]}$ Black female Caribbean and female African American participants who experienced greater support were more likely to follow their dietary plans. Additional studies found social support as an influential predictor in dietary adherence, physical activity, glucose monitoring, and taking medication as recommended. ${ }^{[53,54]}$ Similar to Chlebowy and Garvin, ${ }^{[55]}$ 
this study did not find an association between social support and some self-management behaviors (e.g., diet or physical activity) although Chlebowy and Garvin used general social support instead of diabetes-specific support. Perceived emotional support (i.e. received and provided) was insignificant in the sample. The lack of perceived emotional support may be due to negative family interaction between participants and family members. ${ }^{[36]}$

This study found no association between T2D-specific social support and following a foot care procedure among the sample of Black Caribbean and African American women. This lack of association was in conflict with Belgrave and Lewis, ${ }^{[56]}$ who found a positive association between social support and following a foot care procedure, if the source of support came from their spouse or adult child. Although a positive association was found between social support and certain self-management practices, a negative association was found with physical activity and taking recommended medication. This study's findings emphasize the importance of negative family and other social relationships, which is consistent with Schafer et al.'s ${ }^{[57]}$ research. They found that adults diagnosed with type-1 diabetes who perceived negative social support from family members showed poorer adherence to medication. However, unlike Schafer et al., ${ }^{[57]}$ this study did not find similar findings to glucose testing and diet. Maybe, the perceptions of adults with type- 1 diabetes, that is, seeing negative social support, differed from the observations of adults with T2D.

In a series of studies that have included prospective assessment, Trief et al. ${ }^{[58]}$ and Trief et al.${ }^{[59]}$ demonstrated the importance of paying particular attention to spousal interactions and marital quality in promoting adherence to the diabetes self-management regimen. These two studies highlighted the importance of changes to the social environment that may assist in disease self-management. This study, however, consisted of predominantly unmarried older women, whose social networks consisted of children, other family members, and friends. The study found that female participants were less likely to exercise if they reported wanting more support from family and friends. Family members and friends have greater influence on observable self-management behaviors as opposed to self-management behaviors performed in solitude. ${ }^{[60]}$ Physical activity is an observable behavior that is likely to occur in social settings. This study found that participants were less likely to exercise if they reported wanting more support from family and friends. It is not known if the participants of this study would increase the amount of physical activity if they had support from their family members or friends. Participants in the study may not have exercised as much due to limitations, such as a lack of physical function or multiple chronic conditions. These reported limitations may have been due to more than three chronic conditions (i.e., hypertension, arthritis, and depression), which are associated with lower activity levels. ${ }^{[61,62]}$ Conversely, taking medication is typically a behavior conducted alone. In this study, individuals with T2D may have had less opportunity to receive social reinforcement with reminders to take medication by family members and friends. The reminders may have been viewed as so-called "nagging." The findings, while broadly supportive of our study, raise important new questions about how social relationships affect progressing chronic conditions in an aging population.

The primary limitation of our study is its small sample size. As a result, our findings may be imprecise. In particular, our study included only 42 subjects and was biased toward older female patients. ${ }^{[38,63,64]}$ It is therefore likely that important findings, which are not reflected in the current results, may be found with a larger number of study participants. ${ }^{[38]}$ More studies with larger sample size of Black Caribbean and African American women are needed to measure diabetes specific to social support among multicultural groups. Second, the study was limited by the quality of data used in the analysis. Consequently, it is possible that the female respondents provided answers they considered socially acceptable. ${ }^{[64]}$ Further concerns, which pertained to the study's small sample size, focused exclusively on reproductive outcomes. Despite our small sample size, this study was able to gain valuable insight into the role of social support among diverse black women diagnosed with T2D.

Due to the cross-sectional design, the study design lacks the ability to prove causality. This limitation makes it difficult to determine if social support, desired or received, improves diabetes self-management behaviors. Maybe, individuals who are successfully adhering to self-management behaviors perceive their families as more supportive because of a more general positive view of the world. Longitudinal studies, which are experimental designs that permit the examination of causal elements, qualitative data, and mixed-methods approaches, can also provide important additional information. Future work might focus on creating culturally tailored programs for women with T2D who would benefit from family-centered interventions. Furthermore, future research could evaluate whether or not the intervention served to enhance family support and positively transform health behavior. To ascertain the degree to which the family acts as a facilitator 
Harvey, et al.: Social support and diabetes self-management

or hindrance, the convoy model suggests (1) an examination of the structure of the individual's support networks, (2) the support exchanged, and (3) the evaluation of the support provided. Additional research studies should include elderly Black Caribbean women with diabetes residing in the United States and the USVI and those who have had diabetes for many years. The developmental tasks of the family may differ when compared to African American women with diabetes.

Although self-report is unavoidable and even desirable, other measures would benefit from more objective appraisals of the participants' circumstances. In their self-report of disease management, participants may give biased responses or exaggerate their adherence to their medical regimens. Utilizing self-reported instruments may have influenced the results. In general, future studies should account for these limitations to fully convey the complex nature of diabetes self-management behaviors and social support for Black Caribbean and African American women diagnosed with diabetes. Consideration of more specific measures and a more varied participant population could provide different results. The number of T2D cases continues to rise in North America and the Caribbean, especially within racial and ethnic minority groups. ${ }^{[1]}$ To this end, future research must address the limitations faced in the current study to help Black female Caribbean diabetes patients identify social support to assist with diabetes self-management behaviors.

\section{CONCLUSION}

Despite these limitations, this study has value in providing empirical results among Black Caribbean women and African American women diagnosed with diabetes because these results relate to social support and T2D self-management behaviors. This study suggests directions in future research that would examine the dynamics of social support and T2D self-management behaviors. This study might be relevant to other Caribbean women (non-Afro-Caribbean) with T2D both in North America and in the Caribbean.

\section{Financial support and sponsorship}

Nil.

\section{Conflicts of interest}

There are no conflicts of interest.

\section{REFERENCES}

1. Alwan A. Global Status Report on Noncommunicable Disease; 2010. Geneva, Switzerland: World Health Organization; 2011.
2. Danaei G, Finucane MM, Lu Y, Singh GM, Cowan MJ, Paciorek CJ, et al. National, regional, and global trends in fasting plasma glucose and diabetes prevalence since 1980: Systematic analysis of health examination surveys and epidemiological studies with 370 country-years and $2 \cdot 7$ million participants. Lancet 2011;378:31-40.

3. Whiting DR, Guariguata L, Weil C, Shaw J. IDF diabetes atlas: Global estimates of the prevalence of diabetes for 2011 and 2030. Diabetes Res Clin Pract 2011;94:311-21.

4. Chen L, Magliano DJ, Zimmet PZ. The worldwide epidemiology of type 2 diabetes mellitus - Present and future perspectives. Nat Rev Endocrinol 2011;8:228-36.

5. Strom JL, Egede LE. The impact of social support on outcomes in adult patients with type 2 diabetes: A systematic review. Curr Diab Rep 2012;12:769-81.

6. American Diabetes Association. Diagnosis and classification of diabetes mellitus. Diabetes Care 2010;33 Suppl 1:S62-9.

7. Zimmet P, Alberti KG, Shaw J. Global and societal implications of the diabetes epidemic. Nature 2001;414:782-7.

8. Mokdad AH, Bowman BA, Ford ES, Vinicor F, Marks JS, Koplan JP. The continuing epidemics of obesity and diabetes in the United States. JAMA 2001;286:1195-200.

9. Centers for Disease Control and Prevention. National Diabetes Fact Sheet: Estimates of Diabetes and its Burden in the United States, 2014. U.S. Department of Health and Human Services. Atlanta; 2014.

10. Ford ND, Narayan KM, Mehta NK. Diabetes among US- and foreign-born blacks in the USA. Ethn Health 2016;21:71-84.

11. Bennett NR, Francis DK, Ferguson TS, Hennis AJ, Wilks RJ, Harris EN, et al. Disparities in diabetes mellitus among Caribbean populations: A scoping review. Int J Equity Health 2015;14:23.

12. Hennis A, Wu SY, Nemesure B, Li X, Leske MC; Barbados Eye Study Group. Diabetes in a Caribbean population: Epidemiological profile and implications. Int J Epidemiol 2002;31:234-9.

13. Nunez MA, Yarandi H, Nunez-Smith M. Self-management among patients living with diabetes in the United States Virgin Islands. J Health Care Poor Underserved 2011;22:271-83.

14. Yisahak SF, Beagley J, Hambleton IR, Narayan KM; IDF Diabetes Atlas. Diabetes in North America and the Caribbean: An update. Diabetes Res Clin Pract 2014;103:223-30.

15. Washington RE, Orchard TJ, Arena VC, Laporte RE, Tull ES. Incidence of type 1 and type 2 diabetes in youth in the U.S. Virgin Islands, 2001-2010. Pediatr Diabetes 2013;14:280-7.

16. Boyne MS. Diabetes in the Caribbean: Trouble in paradise. Insulin 2009;4:94-105.

17. Callwood GB, Campbell D, Gary F, Radelet ML. Health and health care in the U.S. Virgin Islands: Challenges and perceptions. ABNF J 2012;23:4-7.

18. Stopford R, Winkley K, Ismail K. Social support and glycemic control in type 2 diabetes: A systematic review of observational studies. Patient Educ Couns 2013;93:549-58.

19. Thoits PA. Mechanisms linking social ties and support to physical and mental health. J Health Soc Behav 2011;52:145-61.

20. Cohen S. Psychosocial models of the role of social support in the etiology of physical disease. Health Psychol 1988;7:269-97.

21. Seeman TE. Health promoting effects of friends and family on health outcomes in older adults. Am J Health Promot 2000;14:362-70.

22. Kahn RL, Antonucci TC. Convoys over the life-course: Attachment, roles, and social support. In: Baltes PB, Brim OG, editors. Life-Span Development and Behavior. Vol. 3. San Diego: Academic Press; 1980. p. 253-86.

23. Antonucci TC, Jackson JS. Social support, interpersonal efficacy, and health. In: Carstensen LL, Edelstein BA, editors. Handbook 
Harvey, et al.: Social support and diabetes self-management

of Clinical Gerontology. New York: Pergamon Press; 1987. p. 291-311.

24. Antonucci TC, Akiyama H. Conveys of social relations: Family and friendships within a life span contest. In: Blieszner R, Bedford VH, editors. Handbook of Aging and the Family. Westport, CT: Greenwood Press; 1995. p. 355-72.

25. Antonucci TC. Social supports and social relationships. In: Binstock R, George LK, editors. Handbook of Aging and Social Sciences. $3^{\text {rd }}$ ed. San Diego: Academic Press; 1990. p. 205-26.

26. Antonucci TC. Social relations: An examination of social networks, social support and sense of control. In: Birren JE, Schaie KW, editors. Life Span Development and Behavior. Vol. 3. New York: Academic Press; 2001. p. 427-53.

27. Antonucci TC, Wong KM. Public health and the aging family. Public Health Rev 2010;32:512-31.

28. Tang TS, Funnell MM, Sinco B, Spencer MS, Heisler M. Peer-led, empowerment-based approach to self-management efforts in diabetes (PLEASED): A randomized controlled trial in an African American Community. Ann Fam Med 2015;13 Suppl 1:S27-35.

29. Gucciardi E, Chan VW, Manuel L, Sidani S. A systematic literature review of diabetes self-management education features to improve diabetes education in women of Black African/Caribbean and Hispanic/Latin American ethnicity. Patient Educ Couns 2013;92:235-45.

30. Oftedal B, Bru E, Karlsen B. Social support as a motivator of self-management among adults with type 2 diabetes. J Nurs Healthc Chronic Illn 2011;3:12-22.

31. Shaw BA, Gallant MP, Riley-Jacome M, Spokane LS. Assessing sources of support for diabetes self-care in urban and rural underserved communities. J Community Health 2006;31:393-412.

32. Tang TS, Brown MB, Funnell MM, Anderson RM. Social support, quality of life, and self-care behaviors among African Americans with type 2 diabetes. Diabetes Educ 2008;34:266-76.

33. van Dam HA, van der Horst FG, Knoops $L$, Ryckman RM, Crebolder HF, van den Borne BH. Social support in diabetes: A systematic review of controlled intervention studies. Patient Educ Couns 2005;59:1-12.

34. Samuel-Hodge CD, Headen SW, Skelly AH, Ingram AF, Keyserling TC, Jackson EJ, et al. Influences on day-to-day self-management of type 2 diabetes among African-American women: Spirituality, the multi-caregiver role, and other social context factors. Diabetes Care 2000;23:928-33.

35. Majeed-Ariss R, Jackson C, Knapp P, Cheater FM. A systematic review of research into black and ethnic minority patients' views on self-management of type 2 diabetes. Health Expect 2015;18:625-42.

36. DePalma MT, Rollison J, Camporese M. Psychosocial predictors of diabetes management. Am J Health Behav 2011;35:209-18.

37. Madden MH, Tomsik P, Terchek J, Navracruz L, Reichsman A, Clark TC, et al. Keys to successful diabetes self-management for uninsured patients: Social support, observational learning, and turning points: A safety net providers' strategic alliance study. J Natl Med Assoc 2011;103:257-64.

38. Hertzog MA. Considerations in determining sample size for pilot studies. Res Nurs Health 2008;31:180-91.

39. Fitzgerald JT, Davis WK, Connell CM, Hess GE, Funnell MM, Hiss RG. Development and validation of the Diabetes Care Profile. Eval Health Prof 1996;19:208-30.

40. Fitzgerald JT, Anderson RM, Gruppen LD, Davis WK, Aman LC, Jacober SJ, et al. The reliability of the Diabetes Care Profile for African Americans. Eval Health Prof 1998;21:52-65.

41. Davis WK, Hess GE, Harrison RV, Hiss RG. Psychosocial adjustment to and control of diabetes mellitus: Differences by disease type and treatment. Health Psychol 1987;6:1-14.

42. Connell CM, Fisher EB, Houston CA. Relationships among social support, diabetes outcomes, and morale for older men and women. J Aging Health 1992;4:77-100.

43. Nunnally JC. An overview of psychological measurement. In: Wolman BB, editor. Clinical Diagnosis of Mental Disorders. New York: Springer; 1978. p. 97-146.

44. Toobert DJ, Glasgow RE. Assessing diabetes self-management: The summary of diabetes self-care activities questionnaire. In: Bradley C, editor. Handbook of Psychology and Diabetes: A Guide to Psychological Measurement in Diabetes Research and Practice. $1^{\text {st }}$ ed. Amsterdam, The Netherlands: Harwood Academic Publishers; 1994. p. 351-75.

45. Toobert DJ, Hampson SE, Glasgow RE. The summary of diabetes self-care activities measure: Results from 7 studies and a revised scale. Diabetes Care 2000;23:943-50.

46. Ciechanowski PS, Katon WJ, Russo JE. Depression and diabetes: Impact of depressive symptoms on adherence, function, and costs. Arch Intern Med 2000;160:3278-85.

47. Delahanty LM, Grant RW, Wittenberg E, Bosch JL, Wexler DJ, Cagliero $\mathrm{E}$, et al. Association of diabetes-related emotional distress with diabetes treatment in primary care patients with type 2 diabetes. Diabet Med 2007;24:48-54.

48. Vest BM, Kahn LS, Danzo A, Tumiel-Berhalter L, Schuster RC, Karl R, etal. Diabetes self-management in a low-income population: Impacts of social support and relationships with the health care system. Chronic IIIn 2013;9:145-55.

49. Sarkadi A, Rosenqvist U. Social network and role demands in women's type 2 diabetes: A model. Health Care Women Int 2002;23:600-11.

50. Thomas JL, Stewart DW, Lynam IM, Daley CM, Befort C, Scherber RM, et al. Support needs of overweight African American women for weight loss. Am J Health Behav 2009;33:339-52.

51. Gerstle JF, Varenne H, Contento I. Post-diagnosis family adaptation influences glycemic control in women with type 2 diabetes mellitus. J Am Diet Assoc 2001;101:918-22.

52. Whittemore R, D'Eramo Melkus G, Grey M. Metabolic control, self-management and psychosocial adjustment in women with type 2 diabetes. J Clin Nurs 2005;14:195-203.

53. Albright TL, Parchman M, Burge SK; RRNeST Investigators. Predictors of self-care behavior in adults with type 2 diabetes: An RRNeST study. Fam Med 2001;33:354-60.

54. Garay-Sevilla ME, Nava LE, Malacara JM, Huerta R, Díaz de León J, Mena A, et al. Adherence to treatment and social support in patients with non-insulin dependent diabetes mellitus. J Diabetes Complications 1995;9:81-6.

55. Chlebowy DO, Garvin BJ. Social support, self-efficacy, and outcome expectations: Impact on self-care behaviors and glycemic control in Caucasian and African American adults with type 2 diabetes. Diabetes Educ 2006;32:777-86.

56. Belgrave FZ, Lewis DM. The role of social support in compliance and other health behaviors for African Americans with chronic illnesses. J Health Soc Policy 1994;5:55-68.

57. Schafer LC, McCaul KD, Glasgow RE. Supportive and nonsupportive family behaviors: Relationships to adherence and metabolic control in persons with type I diabetes. Diabetes Care 1986;9:179-85.

58. Trief PM, Grant W, Elbert K, Weinstock RS. Family environment, glycemic control, and the psychosocial adaptation of adults with diabetes. Diabetes Care 1998;21:241-5.

59. Trief PM, Ploutz-Snyder R, Britton KD, Weinstock RS. The relationship between marital quality and adherence to the 
diabetes care regimen. Ann Behav Med 2004;27:148-54.

60. Skelly AH, Dougherty M, Gesler WM, Soward AC, Burns D, Arcury TA. African American beliefs about diabetes. West J Nurs Res 2006;28:9-29.

61. Lee IM, Shiroma EJ, Lobelo F, Puska P, Blair SN, Katzmarzyk PT; Lancet Physical Activity Series Working Group. Effect of physical inactivity on major non-communicable diseases worldwide: An analysis of burden of disease and life expectancy. Lancet
2012;380:219-29.

62. Strawbridge WJ, Deleger S, Roberts RE, Kaplan GA. Physical activity reduces the risk of subsequent depression for older adults. Am J Epidemiol 2002;156:328-34.

63. Hill R. What sample size is "enough" in Internet survey research. Interpers Comput Technol 1998;6:1-10.

64. van Belle G. Statistical Rules of Thumb. $2^{\text {nd }}$ ed. Hoboken, NJ: John Wiley and Sons; 2011. 